\title{
GENDER-BASED DIFFERENCES IN THE BLEEDING TIME AND CLOTTING TIME AND THEIR RELATIONSHIP WITH THE BLOOD GROUPS
}

\author{
Silpa Gantela1, Mahathi Thotakura²
}

${ }_{1}^{1}$ Associate Professor, Department of Physiology, Katuri Medical College.

${ }^{2}$ Assistant Professor, Department of Pathology, Katuri Medical College.

\begin{abstract}
BACKGROUND
The clinical significance of the ABO blood group system extends beyond transfusion medicine. It is remarkable that 100 years after the work of Karl Landsteiner (1900) on blood grouping, the scene is different and numerous studies have been carried out on association of blood groups with diseases. But, very less research is done on association of blood groups with other haematological parameters like bleeding time and clotting time.

The aim of the present study is to establish a relationship between blood groups and bleeding time, clotting time and to observe if there is any gender-based differences of the same.
\end{abstract}

\section{MATERIALS AND METHODS}

In order to add to the existing knowledge on the subject, we studied 150 normal healthy subjects (Medical students) to find out the probable relationship between Blood groups and gender with bleeding time \& clotting time. Blood group determination was done by mixing the sample of blood with antisera A and B and Anti D antisera and was confirmed by looking for clumping of RBCs und er the microscope. Bleeding time was estimated by Duke Method and clotting time was estimated by capillary tube method.

\section{RESULTS}

In our study, we observed that the 0 blood group individuals are having greater bleeding time and clotting time than the non- 0 blood group individuals. Females had more bleeding time and clotting time than males.

\section{CONCLUSION}

So, through this research, the fact that there is a gender-based difference in the Bleeding time and Clotting time is proven. The relationship between bleeding time and clotting time with the blood groups was also studied.

\section{KEYWORDS}

Bleeding Time, Clotting Time, Blood Groups.

HOW TO CITE THIS ARTICLE: Gantela S, Thotakura M. Gender-based differences in the bleeding time and clotting time and their relationship with the blood groups. J. Evolution Med. Dent. Sci. 2017;6(91):6399-6402, DOI: 10.14260/jemds/2017/1391

\section{BACKGROUND \\ In the year 1900, scientist Karl Landsteiner identified the ABO} system of blood group which was the starting of Blood Banking and Transfusion Medicine.(1) The clinical significance of the ABO blood group system extends beyond transfusion medicine and several reports have suggested an important involvement in the development of cardiovascular, oncological and other diseases(2) associated with hypercoagulability.(3,4) Some of the stranger and more ridiculous associations, including a more pronounced hangover in group A individuals, better teeth in group 0 persons, personality traits, the intelligence quotient, the socioeconomic profile of the population, and digestion were all reviewed by George Garrett and were also published in highly respected journals, such as Nature in 1973 and 1984, or in several books, the last of which was in 1999. Bleeding time is the time taken from the puncture of the blood vessel to the stoppage of bleeding.

'Financial or Other Competing Interest': None.

Submission 06-10-2017, Peer Review 08-11-2017,

Acceptance 15-11-2017, Published 27-11-2017.

Corresponding Author:

Silpa Gantela,

Flat No. 003,

Sri Suryachandra Residency,

Brodipet 1/18, Guntur-522006.

E-mail:shilpagantela@gmail.com

DOI: $10.14260 /$ jemds/2017/1391

\section{(c) $($ ) $\odot$}

Clotting time is the time taken from the puncture of the blood vessel to the formation of the fibrin thread. Evaluation of haemostasis is an essential factor for surgeons and anaesthetists before undertaking any surgical procedure.

Hence, it is a routine preoperative test for hospitals. Almost 13 clotting factors and von Willebrand factor is associated with the coagulation process. A clear correlation has been established between the ABO phenotype and the level of two proteins in blood clotting i.e. factor VIII and von Willebrand factor (vWF). The relationship between bleeding time, clotting time and blood groups is important in certain clinical conditions like epistaxis, cardiac surgery or thrombosis, etc. Studies have reported that half of the epistaxis patients had blood group $\mathrm{O}$ and blood group $\mathrm{O}$ was associated with a lower expression of vWF (Von Willebrand factor) as compared with non-O groups. A longer bleeding time was demonstrated in patients with group 0 compared with non-0 groups.(5)

\section{Aims \& Objectives}

1. To assess the distribution of blood groups.

2. To find out if there is any relationship of gender with bleeding time and clotting time.

3. To find out if there is any definite relationship between the blood groups and bleeding time and clotting time in our population. 


\section{MATERIALS \& METHODS}

This observational study was conducted in the Department of Physiology in Katuri Medical College. In our institution, it is mandatory for all the medical students to do their blood grouping, bleeding time and clotting time during their 1 st year of study as a part of their training program. Informed consent was taken from every student participating in the study. The available detail reports of 215 medical students were analysed in respect of age, sex, blood group, bleeding time and clotting time.

\section{Inclusion Criteria}

150 Medical students from First year MBBS.

\section{Exclusion Criteria}

Students with any history of bleeding disorders and who are using Drugs like NSAIDs are excluded from the study.

\section{Statistical Analysis}

Statistical analysis was done with appropriate statistical tools. Blood grouping, bleeding time and clotting time were estimated. Mean, Standard deviation was calculated. P value was calculated. One way Chi square test and correlation test are used to analyse the data. IBM-compatible Statistical Package for the Social Sciences (SPSS) version 20.0 was used for Statistical analysis. P-value at $<0.05$ was considered significant and at $<0.001$ was considered highly significant, while at $>0.05$ was considered not significant. The qualitative data were expressed as number (\%), while the continuous quantitative data as mean \pm standard deviation (SD).

\section{Benefits}

1. Having a non-O blood group is associated with an increased risk of VTE (17) and that the addition of thrombophilia increases the thrombotic risk conferred by non-0 group alone by almost 3 -fold. This simple information may help to identify groups of patients at high risk suitable for counselling, further testing or closer monitoring.

2. The 0 blood group individuals can be educated on the role of blood group in the epistaxis and proper preventive measures can be taken. Blood group determination was done by mixing the sample of blood with antisera A and B and Anti D antisera and was confirmed by looking for clumping of RBCs under the microscope. Bleeding time was estimated by Duke Method and clotting time was estimated by capillary tube method.

\section{Dukes Method}

It is convenient and commonly used method. The stop watch is set at zero. The tip of the finger is cleaned thoroughly with spirit and allowed to dry. A puncture is made deep enough (about 3-4 mm) to ensure free flow of blood without squeezing. Immediately the stop watch is started. The time of puncture of the finger is referred as zero time. 30 seconds later the escaping blood is dried on the edge of a clean piece of filter paper. This procedure is repeated every 30 seconds using a fresh area of the paper until bleeding ceases and no further blood spot appears on the filter paper. Therefore, each blot of blood on the filter paper represents 30 seconds flow of blood. The total number of blood spots on the filter paper are counted and multiplied by $1 / 2$. This will give the bleeding time in minutes. Normal bleeding time by this method is 2-6 minutes.

\section{Capillary Glass Tube Method}

This is the most convenient and commonly used method in practice. The tip of the finger is cleaned thoroughly with spirit and allowed to dry. A puncture is made deep enough (about 3- $4 \mathrm{~mm}$ ) to ensure free flow of blood without squeezing. The time of puncture of the finger is referred as zero time. When a large drop of blood has collected, the capillary tube will be inserted into the drop holding tube such that its other end will be at a lower level. Blood will flow rapidly into the capillary tube. The capillary tube must be held in between the palm of the hand, so as to maintain it under body temperature. At the end of one minute, break off about one centimetre of the tube from one end and then notice if a thread of fibrin connects the broken ends of the tube. If there is no fibrin thread, repeat the procedure every 30 seconds till a fibrin thread appears. The appearance of fibrin thread of about $5 \mathrm{~mm}$ length indicates that the blood has clotted. The total time taken from the time of puncture (Zero time) till the formation of a fibrin thread is the clotting time. Normal value of clotting time by this method is 3-8 minutes. Finally bleeding time and clotting time of different blood groups were compared and statistical analysis was done.

\section{RESULTS}

In our study, we observed that the 0 blood group individuals are having greater bleeding time and clotting time than the non-O blood group individuals. There was statistical significance among the $\mathrm{ABO}$ groups with clotting time below 4 minutes and above 4 minutes showing $p=0.001$. Again there was statistical significance among the $A B O$ groups with bleeding time below 5 minutes and above 5 minutes showing $\mathrm{p}=0.002$.

$82.75 \%$ of the females had bleeding time greater than 5 minutes and $68.96 \%$ of the females had clotting time $>4$ minutes. The student " $\mathrm{t}$ " test for bleeding time among male and female individuals showed a statistically significant value of $p=0.001$ and for the clotting time the $P$ value was $p=0.002$, which was also statistically significant.

\begin{tabular}{|c|c|c|}
\hline Gender & $<\mathbf{5 ~ m i n .}$ & $>\mathbf{5 ~ m i n .}$ \\
\hline Female 58 & $10(17.24 \%)$ & $48(82.75 \%)$ \\
\hline Male 42 & $35(83.4 \%)$ & $7(16.67 \%)$ \\
\hline \multicolumn{2}{|c|}{ Table 1. Graph Showing Bleeding Time Below and } \\
Above 5 min. on Various Blood Groups \\
\hline
\end{tabular}

\begin{tabular}{|c|c|c|}
\hline Gender & $<4$ min. & $>$ 4 min. \\
\hline Female 58 & $18(31.03 \%)$ & $40(68.96 \%)$ \\
\hline Male 42 & $36(85.71 \%)$ & $6(14.28 \%)$ \\
\hline \multicolumn{2}{|c|}{ Table 2. Gender Difference in Clotting Time } \\
\hline
\end{tabular}

\begin{tabular}{|c|c|c|}
\hline Blood group & $<\mathbf{5 ~ m i n .}$ & $>\mathbf{5 ~ m i n .}$ \\
\hline $\mathrm{O}(66)$ & $(16) 24 \%$ & $(50) 76 \%$ \\
\hline $\mathrm{A}(25)$ & $(17) 68 \%$ & $(8) 32 \%$ \\
\hline $\mathrm{B}(30)$ & $(22) 72 \%$ & $(8) 28 \%$ \\
\hline AB (29) & $(24) 83 \%$ & $(5) 17 \%$ \\
\hline \multicolumn{3}{|c|}{ Table 3. Distribution of Bleeding Time in Different Blood } \\
Groups \\
\hline
\end{tabular}




\begin{tabular}{|c|c|c|}
\hline Blood Group & <4 Min. & >4 Min. \\
\hline O (66) & $(15) 22 \%$ & $(51) 78 \%$ \\
\hline A (25) & $(18) 70 \%$ & $(7) 30 \%$ \\
\hline B (30) & $(23) 74 \%$ & $(7) 26 \%$ \\
\hline AB (29) & $(25) 84 \%$ & (4) $16 \%$ \\
\hline \multicolumn{2}{|c|}{ Table 4. Distribution of Clotting Time Indifferent } \\
Blood Groups \\
\hline
\end{tabular}

\section{DISCUSSION}

Plenty of publications in medical-scientific literature deal with Gender-based differences in the bleeding time and clotting time and their relationship with the blood groups.

In a study done by Dr. Sasekala (6)M, Dr. P. Saikumar titled Relationship Between Bleeding Time And Clotting Time And Gender Difference And Varying Blood Groups In UG Medical Students, clotting time was prolonged in group B persons than the blood group 0 which was statistically significant $(p<0.02)$ whereas bleeding time was significantly more in $A B$ group persons than in persons with blood group 0 and there was no significant difference in clotting time and bleeding time in both the sexes.

Another publication titled Blood Group Distribution and Its Relationship with Bleeding Time and Clotting Time: A Medical School Based Observational Study among Nepali, Indian and Sri Lankan Students(7) published in Nepal Journal of Epidemiology suggests that $\mathrm{O}$ blood group is predominant in Nepalese students while Blood group B was the most common blood group in the Indian students. They also found higher BT and CT in females, more prominent in Indians, so this gender disparity is an additional risk factor for them.

In a study on Gender Based Blood Group Distribution and Its Relationship With Bleeding Time And Clotting Time In Medical Students(8) by Nadera Yasmeen, Imtiaz A Liand Rashid Shaikh published in Biomedical and Pharmacology Journal, it is found that $\mathrm{O}$ blood group is more prevalent in both the sexes (25\% in males and $14.5 \%$ in females) than A, B and $\mathrm{AB}$. Clotting time is found to be more in $\mathrm{O}$ Blood group in females, whereas bleeding time in different blood groups did not show any change in both the sexes.

A retrospective study on Relationship of Bleeding Time and Clotting Time with Blood Groups.(9) was carried out in Dept. of Physiology at Punjab Institute of Medical Sciences, Jalandhar, Punjab on 215 medical students. The results were analysed and it was found that BT in blood group B was significantly raised as compared to other blood groups $(p<0.01)$. However, the correlation between CT of different blood groups was not significant.

Studies have reported that half of the epistaxis patients had blood group 0 and blood group $\mathrm{O}$ was associated with a lower expression of vWF (Von Willebrand factor) $(10,11$,) as compared with non-O groups. Longer bleeding time was demonstrated in patients with group 0 compared with non-O groups.

The relationship between blood group and epistaxis among the patients coming to Tribhuvan University Teaching Hospital, Kathmandu with idiopathic epistaxis was studied. A total of 235 patients coming to the Emergency Department or Department of Otorhinolaryngology with active nose bleeding were included. ABO blood grouping was performed. Nearly half $(45.5 \%)$ of the patients belonged to O-group followed by
A-group. 0-group people also had longer bleeding time compared to other blood groups. (12)

A clear correlation has been established between the ABO phenotype and the level of two proteins in blood clotting i.e. factor VIII and von Willebrand factor (vWF).(13,14) Individuals with blood group 0 have about $25 \%$ less factor VIII and vWF in their plasma, thus increasing their clotting time and may cause excessive bleeding.

More consistent data are available in the literature regarding the $\mathrm{ABO}$ blood group-related risk of venous thromboembolism (VTE).(15)

For instance, Wauthrecht(16) and colleagues, found a significantly higher frequency of non-0 blood group in 369 patients with a diagnosis of deep vein thrombosis as compared with the frequency in 49,373 healthy blood donors (70.6\% vs. $53.9 \%$, p<0.001).

A study titled Risk of Gastric Cancer(17) and Peptic Ulcers in Relation to ABO Blood Type- A Cohort Study confirmed that blood group A is indeed associated with a higher risk of gastric cancer compared to blood group 0 .

\section{CONCLUSION}

This current research activity on Gender-based differences in the Bleeding time and Clotting time and their relationship with the Blood groups will surely help bring awareness amongst all individuals about the inherited risk they are exposed to. This study on association of blood grouping with bleeding and clotting time will bring more awareness to the health care communities in prevention of the above diseases by appropriate measures in the concerned individuals. Health care ministries might want to sponsor researches on blood grouping to prevent complications like post-surgical haemorrhages.

\section{Limitations to the Study}

The results were statistically significant; however, as we only looked at Katuri Medical College students, these findings may not translate to subjects of other areas.

\section{REFERENCES}

[1] Storry JR, Olsson ML. The ABO blood group system revisited: a review and update. Immunohematology 2009;25(2):48-59.

[2] Garratty G. Blood groups and disease: a historical perspective. Transfus Med Rev 2000;14(4):291-301.

[3] Franchini M, Favaloro EJ, Targher G, et al. ABO blood group, hypercoagulability, and cardiovascular and cancer risk. Crit Rev Clin Lab Sci 2012;49(4):137-49.

[4] Franchini M, Capra F, Targher G, et al. Relationship between $\mathrm{ABO}$ blood group and von Willebrand factor levels: from biology to clinical implications. Thromb J 2007;5:14.

[5] Welsby IJ, Jones R, Pylman J, et al. ABO blood group and bleeding after coronary artery bypass graft surgery. Blood Coagul Fibrinolysis 2007;18(8):7815.

[6] Sasekala M, Saikumar P. Relationship between bleeding time and clotting time among gender difference and varying blood groups in UG medical students. Journal of Dental and Medical Sciences 2013;10(6):40-3. 
[7] Roy B, Banerjee I, Sathian B, et al. Blood group distribution and its relationship with bleeding time and clotting time: a medical school based observational study among Nepali, Indian and Sri Lankan students. Nepal Journal of Epidemiology 2011;1(4):135-40.

[8] Yasmeen N, Ali I, Shaikh R. Gender based blood group distribution and its relationship with bleeding time and clotting time in medical students. Biomedical \& Pharmacology Journal 2014;7(2):61921.

[9] Kohli PG, Kaur H, Maini S. Relationship of bleeding time and clotting time with blood groups. Research Journal of Pharmaceutical, Biological and Chemical Sciences 2014;5(2):1780-3.

[10] Reddy VM, Daniel M, Bright E, et al. Is there an association between blood group 0 and epistaxis? J Laryngol Otol 2008;122(4):366-8.

[11] Favaloro EJ, Soltani S, McDonald J, et al. Reassessment of ABO blood group, sex and age on laboratory parameters used to diagnose von Willebrand disorder: potential influence on the diagnosis vs the potential association with risk of thrombosis. Am J Clin Pathol 2005;124(6):910-7.
[12] Daniel M, Jaberoo MC, Stead RE, et al. Is admission for epistaxis more common in Caucasian than in Asian people? A preliminary study. Clin Otolaryngol 2006;31(5):386-9.

[13] Adhikari P, Pramanik T, Pokharel R, et al. Relationship between blood group and epistaxis among Nepalese. Nepal Med Coll J 2008;10(4):264-5.

[14] Gill JC, Brooks EJ, Bauer PJ, et al. The effect of ABO blood group on the diagnosis of von Willebrand disease. Blood 1987;69(6):1691-5.

[15] Spiezia L, Campello E, Bon M, et al. ABO blood groups and the risk of venous thrombosis in patients with inherited thrombophilia. Blood Transfus 2013;11(2):250-3.

[16] Wautrecht JC, Galle C, Motte S, et al. The role of ABO blood groups in the incidence of deep vein thrombosis. Thromb Haemost 1998;79(3):688-9.

[17] Edgren G, Hjalgrim H, Rostgaard K, et al. Risk of gastric cancer and peptic ulcers in relation to $\mathrm{ABO}$ blood type: a cohort study. Am J Epidemiol 2010;172(11):1280-5. 